\title{
OS IMPACTOS DA ADOÇÃO DE PROGNÓSTICOS DE RISCOS NO POLICIAMENTO SOB A SELETIVIDADE PENAL E AS DESIGUALDADES SOCIAIS
}

\author{
Lorena Melo Coutinho* \\ Priscilla Macêdo ${ }^{* *}$
}

\begin{abstract}
Resumo: No cenário atual, em que mecanismos matemáticos e estatísticos se destacam na resolução das adversidades sociais - em virtude da suposta precisão e certeza conferida pelos mesmos -, os prognósticos de riscos, edificados por lógica algorítmica, ganham proeminência destinando-se à prática do policiamento preditivo. O presente estudo, explicativo-descritivo, empregou as modalidades bibliográfica e documental, e objetiva analisar como a adoção de prognósticos de riscos no policiamento impacta a seletividade penal e as desigualdades sociais. A pesquisa provoca inquietações que incentivam novos estudos, apresenta questionamentos sobre a suposta eficiência de prognósticos de riscos e orienta possíveis caminhos para a atuação policial.

Palavras-chave: Prognósticos de riscos; Algoritmos; Policiamento preditivo; Seletividade penal; Desigualdade social.

\section{THE IMPACTS OF ADOPTION OF RISK PROGNOSTICS ON POLICY UNDER CRIMINAL SELECTIVITY AND SOCIAL INEQUALITIES}

\begin{abstract}
In the current scenario, in which mathematical and statistical mechanisms stand out in the resolution of social adversities - due to the supposed precision and certainty conferred by them - the risk prognosis, built by algorithmic logic, gain prominence for the purpose of predictive policing. This explanatory-descriptive study used bibliographic and documentary modalities, and aims to analyze how the adoption of risk prognosis in policing impacts criminal selectivity and social inequalities. The research provokes concerns that encourage new studies, raises questions about the supposed efficiency of risk predictions and guides possible paths for police action.
\end{abstract}

Keywords: Risk prognosis; Algorithms; Predictive policing; Criminal selectivity; Social inequality.

\section{INTRODUÇÃO}

A tentativa por sistematizar e mecanizar as tomadas de decisões, fazendo com que as mesmas se distanciem de uma análise clínica em direção a uma majoritariamente estatística e matemática, é tendência em adoção crescente para a resolução dos mais diversos problemas, e no campo da criminalidade a propensão não é diferente. Há uma crença geral sobre a certeza e

\footnotetext{
* Mestranda em Ciências Criminais pela PUC/RS. Especialista em Direito Penal e Criminologia pela PUC/RS. Bacharela em Direito pela Unit/SE. Advogada. Aracaju/SE. E-mail: lorenacoutinho903@gmail.com

*** Mestranda em Ciências Criminais pela PUC/RS. Especialista em Direito Penal e Processual Penal pela Unit/AL. Bacharela em Direito pela UFAL. Advogada. Maceió/AL. E-mail: priscilla.m@edu.pucrs.br
} 
a exatidão possíveis de ser alcançadas através dos números e, em busca dessa objetividade, os prognósticos de riscos, edificados através de algoritmos, encontram seu campo de destaque.

Os algoritmos são códigos utilizados para a resolução de adversidades e que apresentam constantemente respostas semelhantes orientadas pela definição de sucesso atribuída pelo(s) indivíduo(s) que o programou. Nesse sentido, desde já é de se imaginar que estender essa lógica extremamente objetiva, pragmática e estática para buscar solucionar problemas relativos à criminalidade significa desconsiderar a exigência de reflexões com maior teor de criticidade e subjetividade que este assunto requer.

O poder estatal que apresenta maior performance enérgica, incisiva e até bélica no combate à criminalidade é o órgão policial, e é exatamente sob a atuação deste que o presente trabalho voltará os seus estudos, ante a crescente discussão sobre policiamento preditivo. $\mathrm{O}$ policiamento preditivo se realiza através da utilização de prognósticos de risco pela polícia, a fim de determinar - e posteriormente fiscalizar e controlar com maior intensidade - locais e sujeitos julgados propensos à prática delitiva.

Acontece que, como já mencionado, partindo da concepção de que os algoritmos funcionam gerando uma espécie de respostas idênticas com base nas concepções de sucesso do(s) sujeito(s) que o construiu, e também que o pensamento histórico brasileiro é essencialmente discriminatório - principalmente racista -, emerge a seguinte problemática que enseja a presente pesquisa: "Como a adoção de prognósticos de risco no policiamento impacta a seletividade do sistema penal e as desigualdades sociais?.".

No caminho a ser percorrido durante a pesquisa, a fim de que seja efetivamente possível responder o problema acima apresentado, será imprescindível descrever o mecanismo de funcionamento dos algoritmos e a lógica por detrás dos mesmos, afinal, são eles que guiam o funcionamento dos prognósticos de riscos, os quais conduzem e protagonizam esse estudo. Ademais, também será necessário pontuar as mentalidades e as diretrizes verificadas como norteadoras do exercício da atividade policial, através da análise do panorama histórico que nos direciona à compreensão do cenário atual e das perspectivas de futuro.

O exercício do policiamento preditivo é uma temática que figura atualmente como palco emergente de discussões sobre a sua aplicação, e, ao que tudo indica, por muito tempo permanecerá, ante a sua relação com o desenvolvimento de novas tecnologias. De antemão, 
portanto, em virtude dessa contemporaneidade e do crescimento de debates que envolvem esse entorno, observa-se a importância em debruçar-se nos estudos da temática.

O presente trabalho contribuirá para o enriquecimento dos estudos, juntamente com os demais até então realizados, bem como incentivará a continuidade dos trabalhos que de alguma forma atinjam os entornos da mesma temática.

Além disso, com a obtenção das considerações finais deste trabalho, isto é, após a analise da influência exercida por prognósticos de risco adotados em âmbito policial precisamente com relação à seletividade do sistema penal e às desigualdades sociais - será possível determinar as consequências da aplicação de tais métodos guiados por algoritmos, e, com isso, orientar possíveis caminhos para a atuação da polícia brasileira que sigam em direção dos fundamentos democráticos, com destaque ao princípio da equidade.

De forma geral, apoiadores do policiamento preditivo acreditam que este mecanismo seria capaz de resolver a problemática criminal no país. Nesse sentido, ponderando, por um lado, o pensamento acima apresentado de que a adesão à linguagem racional e matemática dos prognósticos de riscos para determinar o direcionamento da atividade policial representaria uma espécie de "salvação", e, por outro, considerando estudos anteriores acerca do caráter discriminatório do policiamento, nascem as curiosidades e reflexões que conduzem à principal motivação para a realização da presente pesquisa.

Partindo-se da perspectiva que o pensamento neoliberal distingue as vidas dos sujeitos integrantes de uma mesma comunidade em graus de importância - "irrelevantes“ ou "relevantes" -, bem como considerando que mais de 50\% da população brasileira se declara negra, segundo a Pesquisa Nacional por Amostra de Domicílios (Pnad) Contínua do IBGE, e que, além disso, o Brasil conta com a $2^{a}$ maior concentração de renda do mundo, conforme o Relatório de Desenvolvimento Humano da Organização das Nações Unidas, este trabalho acadêmico pretende estudar de forma crítica se a utilização de prognósticos de riscos para fundamentar o direcionamento da atuação policial contribui para a solidificação e a naturalização das desigualdades sócio raciais historicamente existentes no país. E, em caso de resposta afirmativa, de que forma isso acontece.

O presente estudo reconhece o quão vasta é a temática e assim não pretende esgotála, no entanto, juntamente aos demais trabalhos já desempenhados, engrandece o debate atual sobre a importância do conhecimento dos entornos da criminalidade, do mecanismo de funcionamento por detrás dos algoritmos e dos processos de criminalização, contribuindo para 
o esclarecimento e verificação da ideia de uma suposta eficiência alimentada pela estratégia da adoção de prognósticos de riscos.

A fim de que seja possível responder o problema objeto de estudo, bem como a consecução dos objetivos, tanto geral como específicos, a pesquisa assume cunho explicativodescritivo e, no que tange ao procedimento utilizado para a viabilização da coleta de informações, emprega as modalidades bibliográfica e documental. Ademais, toma-se a abordagem qualitativa tendo em vista que é exigida apreciação crítica e aprofundada da pesquisadora, através de uma análise valorativa interpretativa sobre as informações e os discursos apresentados.

Além do diálogo com esse aporte teórico, com as conclusões a serem obtidas ao final da pesquisa - que hoje se tratam de hipóteses -, esse trabalho acadêmico também poderá vir a sugerir a mudança na direção para a qual caminha o Brasil no que tange aos mecanismos justificadores de ordens de policiamento, a fim de que não siga as estratégias norteamericanas, as quais contribuem para a manutenção e a ampliação das desigualdades, como também compromete o Estado Democrático de Direito, por adotar posições antagônicas aos seus preceitos mantenedores.

\section{A LógICA ALgORÍTMICA E SEU PROCESSO ESTIGMATIZANTE NO POLICIAMENTO}

Os avanços nos campos da matemática e da estatística possibilitaram que já no século XIX prognósticos de riscos fossem examinados e utilizados para o desenvolvimento e direcionamento de políticas públicas de segurança. A realidade da adoção destes prognósticos de avaliação de riscos, que, diga-se de passagem, é extremamente perigosa, se expandiu para atingir distintas áreas de atuação, a exemplo da policialesca, com a finalidade de resolver a problemática da criminalidade brasileira, que será nesse trabalho examinada.

O funcionamento de prognósticos de riscos se perfaz através da utilização de algoritmos, os quais "nada mais são do que opiniões incorporadas em um código" (O'NEIL, 2016, tradução nossa ${ }^{1}$ ). Entende-se, portanto, que algoritmo é um verdadeiro tutorial, uma instrução listada passo a passo para chegar a solução de uma problemática, qualquer que seja ela.

\footnotetext{
${ }^{1}$ Do original: (...) algorithms are nothing more than opinions embedded in a code.
} 
Não obstante a sua conceituação até sugira uma praticidade para a resolução de adversidades, a aplicação dessa ferramenta em situações que abarcam as ciências sociais, as quais exigem um maior nível de subjetividade, é bastante perigosa e arriscada porque, além de desconhecermos precisamente como os algoritmos funcionam, temos plena convicção de que as respostas por eles apontadas não representam aquilo que é justo, mas sim aquilo que está informaticamente programado.

Segundo O'Neil (2016, tradução nossa ${ }^{2}$ ), “não existe algoritmo objetivo, porque, no mínimo, a pessoa que constrói o algoritmo define sucesso. E isso geralmente é sucesso para ele." e, posteriormente, a matemática acrescenta que “algoritmos não tomam grandes decisões. Para ser claro, são os seres humanos que criaram os processos pelos quais uma pontuação de um algoritmo acaba sendo uma decisão." (O'NEIL, 2016, tradução nossa ${ }^{3}$ ). Nesse sentido, é necessário desmistificar o pensamento de que as soluções apresentadas por algoritmos seriam justas e objetivas, pois, em verdade, elas simplesmente apresentam o resultado do que seria considerado sucesso para os sujeitos que os confeccionaram, demonstrando extrema parcialidade na sua decisão.

Ademais, considerando que os mesmos são alimentados a partir daquilo que era executado previamente à aplicação dessa ferramenta, e que as práticas anteriores se baseavam em um sistema amplamente preconceituoso - racista, machista, sexista, classista etc. -, a adoção de prognósticos de risco apenas faz ecoar toda essa onda discriminatória, ensejando um “iclo de feedback destrutivo" (O'NEIL, 2016, tradução nossa ${ }^{4}$ ).

Dito isso, a lógica matemática de risco não tem em si uma conotação discriminatória (embora não exista tecnologia neutra), mas os dados que alimentam esses instrumentos foram historicamente construídos com processos de desigualdade e servem assim como justificação para sua continuidade e aprofundamento (AMOORE, 2013, p. 51, apud AMARAL e DIAS, 2019).

No que tange especificamente à esfera policial, campo específico de análise no presente trabalho, a utilização de algoritmos tem o intuito de montar um profiling ${ }^{5}$ de indivíduos, categorizando-os com base em atividades realizadas anteriormente, a fim de

\footnotetext{
${ }^{2}$ Do original: (...) there is no such thing as objective algorithm, because at the very least, the person building the algorithm defines success. And that's usually success for them.

${ }^{3}$ Do original: (...) algorithms don't make big decisions. To be clear, its humans that have set up processes by which a score of an algorithm ends up being a decision.

${ }^{4}$ Do original: (...) destructive feedback loop.

${ }^{5}$ Palavra de origem inglesa que faz referência à atividade de criação de perfil de sujeitos; à prática de categorizar as pessoas e prever seu comportamento de acordo com características individuais.
} 
prever, por exemplo, onde acontecerá os próximos delitos ou quem os cometerá, e, a partir de tais informações, determinar como deve se operar o policiamento. Esse processo de esteriotipação provocado é corroborado pelos doutores Amaral e Dias (2019, p. 22), que asseveram que

(...) quando se projeta a atuação de segurança pública interna com base em algoritmos, utilizando decisões em árvore/rede, realizam-se diversas suposições sobre comportamento e características, o que leva a, por exemplo, delimitar perfis raciais, fisionômicos ou religiosos.

Imersos nessa sociedade tecnológica do controle, as políticas públicas, antes preocupadas em satisfazer seu caráter retributivo, dissuasivo e reformador, através da imposição de castigo aos indivíduos considerados delinquentes, agora se mostram mais interessadas em gerir e administrar o risco, a fim de reduzir as oportunidades de cometimento de delito por meio da intensificação do controle situacional do crime. (GARLAND, 2005, p. 281).

Nessa política de prevenção e de redução de danos, conforme salienta Garland (2005), todos os passos e movimentações das pessoas são meticulosamente observados para que seja possível a identificação de lugares atrativos à prática de eventos criminosos, bem como de padrões de sujeitos que apresentam maior probabilidade de se tornarem alvos, para que posteriormente, a partir de tais informações, interfira-se sob estes "pontos quentes" para torná-los menos tentadores ao crime.

Ocorre que, levando em consideração a característica de repetição programada evidenciada pelo uso de algoritmos e, também, que o mecanismo de determinação de plano de ações policiais antes empregado era preconceituoso, constata-se que a utilização da ferramenta de prognósticos de riscos sustenta a reprodução do sistema discriminatório, em um loop infinito.

Com relação ao funcionamento desses sistemas no exercício da atividade de segurança pública, O'Neil (2016) explica que eles operam através da criação de probabilidades estatísticas. A matemática esclarece que são contabilizados os eventos criminosos por região - e, ainda que não propositadamente, pelos critérios de raça e classe -, e, a partir dessa quantificação, os lugares e os indivíduos que ali residem são qualificados com relação a sua periculosidade.

Nessa mesma linha de pensamento, O'Neil (2016) faz uma relevante crítica à execução do policiamento preditivo ao apresentar a evidência de que, apesar de brancos e 
negros fumarem maconha a taxas semelhantes, estes são presos em escalas muito superiores, e a justificativa dessa disparidade está exatamente na característica pessoal da cor de pele. Esse fato apresentado pela matemática demonstra nitidamente como o aparelhamento do sistema de algoritmos é tendencioso e compactua com o histórico de desigualdades socioeconômicas ao estimular e submeter as comunidades negras e pobres a um policiamento extremamente excessivo e desigual quando comparado aos demais agrupamentos sociais.

Os preconceitos impregnados em uma sociedade, e, nesse caso, nos profissionais da polícia, fazem parte de uma história muito anterior à aplicação de mecanismos preditivos. Eles integram a essência do sujeito e se reproduzem de maneira extremamente cotidiana e corriqueira, muitas vezes até imperceptível ante a sua naturalização.

Nesse sentido, é evidente que simplesmente utilizar de maneira acrítica mecanismos de predição provocará o loop dessas intolerâncias e discriminações presentes na subjetividade do sujeito, inclusive, consoante anuncia Sarah Brayne, quando a nova tecnologia é sobreposta a uma velha estrutura organizacional, problemas antigos se moldam aos contornos da nova tecnologia" (2021, p. 139, tradução nossa ${ }^{6}$ ). A chave, portanto, está em identificar os preconceitos que orientam a atuação policial para então revelar de que formar aplicar os algoritmos a fim de que os mesmos conduzam a um caminho de redução dessas discriminações.

No que tange ao exercício do controle, em que pese os mecanismos de confinamento - marcas essenciais da sociedade disciplinar - ainda se façam presentes atualmente, a constatação do nascimento de uma nova penologia, assim classificada por Feeley e Simon (1992), e a chegada da "sociedade de controle", se perfaz através da elevada carga de atenção dispensada aos dados e ao surveillance. (AMARAL e DIAS, 2019, p. 10).

Diferentemente das sociedades disciplinares em que a assinatura e o número de matrícula eram essenciais pois indicavam, respectivamente, o indivíduo e a posição deste numa massa, nas sociedades de controle a importância é direcionada à linguagem numérica, tendo em vista que o controle passa a ser exercido por meio de cifras, senhas, e que o indivíduo deixa de ser enxergado como uno, para ser considerado "dividual", ou seja, um conjunto formado por várias partes de um todo. (DELEUZE, 1992, p. 222).

\footnotetext{
${ }^{6}$ Do original: (...) when the technology is overlaid onto an old organizational structure, long- standing problems shape themselves to the contours of the new technology.
} 
Nessa nova penologia a linguagem racional e matemática ganham ênfase, com discussões sobre a criminalidade voltadas ao risco, ao perigo e às estatísticas, de forma que o discurso criminológico e até os objetivos atribuídos à punição foram transformados para seguir um viés utilitarista. Essa nova abordagem não apresenta qualquer desígnio em agir diretamente nas causas motivacionais das transgressões penais, para intervir ou reabilitar agressores; a preocupação agora é voltada para identificá-los, classificá-los e gerenciá-los, através de métodos matemáticos de projeção. (FEELEY e SIMON, 1992, p. 452).

A lógica neoliberal tem papel crucial para a construção dessa nova realidade, que é desenhada em torno das ideias de liberdade e perigo. Essa racionalidade, que é muito mais que um sistema econômico, fortalece o poder estatal e legitima os discursos para que políticas de controle, verdadeiramente genocidas, sejam adotadas pelo aparelhamento estatal contra alvos específicos, que são os corpos negros. O Estado, que já animalizava e estigmatizava a comunidade negra encontrou na racionalidade neoliberal o discurso ideal para a continuidade das suas políticas de morte contra esses corpos.

\section{A ELASTICIDADE RELATIVA DE OFENSA AO POLICIAMENTO E A NORMALIZAÇÃO DO ESTADO DE EMERGÊNCIA}

Além disso, tão importante como evidenciar o processo estigmatizante provocado pela utilização dos prognósticos de risco para determinar a forma de execução do policiamento preditivo, é também reconhecer e constatar a ineficiência - e a prejudicialidade - na adoção desses prognósticos com a finalidade de reduzir a criminalidade.

Ora, para compreender o pensamento concernente à incapacidade de algoritmos aplicados no policiamento obterem êxito ao fim que se destinam, é imprescindível conhecer a noção de elasticidade relativa de ofensa ao policiamento, conceituada como "o grau em que as mudanças no policiamento afetam as mudanças no crime“ (HARCOURT, 2005, p. 18, tradução nossa ${ }^{7}$ ). Em outras palavras, tal elasticidade faz referência à capacidade da fiscalização e da vigilância policial sob um determinado agrupamento social minorar as taxas de crimes praticados por essa comunidade. Nesse sentido, resumidamente, ser mais elástico significa dizer que o exercício do policiamento provoca maiores mudanças no comportamento social - reduzindo o cometimento de crimes -; e, ser menos elástico, o contrário.

\footnotetext{
${ }^{7}$ Do original: (...) is the degree to which changes in policing affect changes in offending.
} 
Ademais, não surpreendentemente, assim como as taxas de ofensas são distintas entre os diversos grupos sociais, o nível de elasticidade ao policiamento entre eles também é. Nessa perspectiva, os sujeitos integrantes de grupos perfilados, isto é, grupos mais vigiados e controlados pela polícia pelas práticas de condutas delitivas, são em sua maioria formados por indivíduos socioeconomicamente menos favorecidos. Assim, em decorrência das dificuldades sociais e econômicas vivenciadas, é lógico compreender que esses mesmos sujeitos têm menos elasticidade, ou seja, apresentam uma menor mudança comportamental de práticas delitivas mesmo com o aumento do policiamento (HARCOURT, 2005, p. 18).

Juntamente a isso, entre os grupos não perfilados é muito provável que tais condutas criminosas aumentem, haja vista que não são visados pela polícia e têm menos chances de serem descobertos. Assim, diante desse contexto em que o grupo perfilado, apesar de ser frequentemente vigiado, apresentar uma baixa elasticidade, e, portanto, pouca alteração no sentido de redução das práticas criminosas - pelos mais diversos motivos socioestruturais -, e o grupo não perfilado aumentar suas taxas de infrações ante a pouca vigilância policial entre eles, tudo indica que o índice geral de criminalidade, em cômputos numéricos, aumentará.

Como consequência marcante desse direcionamento infinito ao policiamento preditivo de comunidades hierarquicamente menos favorecidas, as quais são predominantemente compostas por sujeitos negros residentes de espaços geográficos mais carentes, tem-se a manutenção e até o fortalecimento da seletividade do sistema penal, que enxerga as vidas de homens negros, pobres e favelados como inimigos do sistema e alvos a serem combatidos.

Segundo Pilatti (2016), “fomentar o medo para vender segurança é uma fórmula tão antiga quanto disseminada". Nesse sentido, não é de hoje que os discursos governamentais e midiáticos funcionam como combustíveis que colaboram para uma verdadeira criminalização da miséria - como bem descreve Wacquant (2001) -, haja vista que constantemente difundem a ideia de tensão e intranquilidade social, e assim disseminam o sentimento de medo e insegurança entre a população.

Vender a ilusão de que "papai Estado" pode "cuidar das pessoas" e nos proteger contra todo o mal se aceitarmos a ampliação e a intensificação de suas ações repressivas e excludentes tem sido uma estratégia tão reiterada quanto bemsucedida, especialmente nos momentos de crise, quando todos nos sentimos inseguros. (PILATTI, 2016). 
Nesse toar, fortalecido com o apoio popular, que por sua vez clama fervorosamente por mais proteção em decorrência do discurso amedrontador difundido pelos meios de comunicação de massa, o aparelho estatal adota posturas autoritárias de repressão e controle excessivo sob corpos determinados sob o pretexto de promover a segurança e a ordem social. Há de se reconhecer, portanto, que essa política de normalização do estado de emergência, construída a partir de uma ideia de insegurança geral, é uma técnica utilizada pelo próprio governo para focar sua ação e fiscalização em alvos específicos (BIGO, 2006b, apud AMARAL e DIAS, 2019, p. 21), ou seja, para legitimar a necropolítica.

Os discursos interpessoais, institucionais e midiáticos perpetuam uma narrativa, frequentemente tácita, que inferioriza e marginaliza os(as) negros(as) moradores de favelas de maneira estrutural e sistemática, associando-os diretamente ao crime e ao perigo, gerando um medo que é difundido para grande parte dos não moradores de favelas. Logo, pode-se ver com clareza a tentativa de legitimar o exercício do poder soberano de matar na sociedade biopolítica brasileira, perpassando não apenas as instituições, como também a população que clama por sua suposta proteção e fortalecimento contra o perigo, o corpo tido a priori como criminoso devido à sua cor de pele e localidade. (STREVA, 2017, p. 256).

Há a consolidação de um discurso que convalida a extrapolação dos limites do uso força estatal - inclusive mediante violência se for o caso -, e na atuação policial isso não é diferente. Orientada pelo objetivo de promover uma espécie de limpeza populacional, em notória referência à eugenia e à tanatopolítica, as vidas de indivíduos “indesejados“. permanecem ininterruptamente na mira do controle e da vigilância policial, pois a sociedade estaria melhor com a supressão desses representantes da "subclasse“ (BAUMAN, 2013b, p. $10)$.

A adoção de prognósticos de risco para antever a prática de uma ação criminosa e, assim, evitar o seu cometimento foi acertadamente demonstrada pelo conto Minority Report, de Philip K. Dick, que originou um filme de mesmo nome dirigido pelo Steven Spielberg (2002). Na ficção é exibida uma realidade futurista, retratada no ano de 2054, em que o avanço tecnológico possibilitou que sujeitos denominados "precognitivos" visualizem a cena de um crime antes dela ocorrer, e, assim, que alguém seja responsabilizado por uma conduta criminosa sem que a tenha praticado.

Não obstante a obra ficcional ocorra em uma sociedade futurista, resta evidenciado que o meio fantasioso e imaginário já foi ultrapassado e adentrou nos tempos atuais através, 
por exemplo, da utilização de algoritmos para direcionar a ação do policiamento preditivo de sistemas de vigilância de grandes cidades, a citar Berlim, Chicago, Londres, Munique e Paris, como bem exibe o documentário alemão Pre-crime. (HEEDER, HIELSCHER, 2017).

Por fim, a adoção de prognósticos de riscos, em especial para a deliberação das ações policiais, é uma tendência bastante perigosa em constante crescimento mundial, e no Brasil não é diferente. Esse mecanismo não busca entender e muito menos agir sob as causas, sejam elas patólogicas ou sociológicas, por detrás da criminalidade. Ele volta-se simplesmente em exercer da melhor e maior forma o controle e a vigilância de vidas "descartáveis", as quais, não surpreendentemente, são formadas pela classe social mais carente, fortalecendo o modelo racista-biologicista e a seletividade penal, que, por sua vez, penetra no sistema jurídico criminal brasileiro, concorre para a manutenção das desigualdades sociais, impulsiona discursos autoritários e vai de encontro a princípios sustentadores do Estado Democrático de Direito.

\section{CONSIDERAÇÕES FINAIS}

Agrade ou não, os avanços tecnológicos e a busca incessante por eficiência seguirão acontecendo de forma exponencial, e, juntamente a isso, a tendência crescente ao uso de métodos estatísticos em vez de clínicos. Na "Era dos Algoritmos" a utilização de mecanismos de prognósticos de risco é emergente e se faz presente inclusive em situações corriqueiras, no entanto, no Brasil os mesmos ainda não foram aderidos para a organização de um policiamento preditivo, e é importante adotarmos uma postura frequentemente questionadora quanto a essa entrada desses mecanismos, afinal, como bem afirma O'Neil (2016, tradução $\operatorname{nossa}^{8}$ ), " precisamos sacrificar a precisão por justiça“.

A adoção de tais ferramentas também na esfera policial implicaria, necessariamente, na redução da discricionariedade intrínseca - e imprescindível - à efetiva atuação policialesca. Apesar de tal característica essencial ser também relacionada a uma espécie de arbitrariedade, ela também garante o agir policial guiado pela observação, pela experiência e até pela intuição. Em contrapartida, a incorporação de mecanismos orientados por prognósticos de risco, planejados pela busca da eficiência, promoveriam a automação do sistema, de forma que as decisões sobre investigação e prisão seriam tomadas mecanicamente. (DIETER, 2012).

\footnotetext{
${ }^{8}$ Do original: (...) we need to sacrifice accuracy for fairness.
} 
Apesar de ser imprescindível a resistência à adesão dos mecanismos orientados por algoritmos no âmbito policial, como já apresentado, esse é o caminho para o qual caminhamos - o Brasil e todo o mundo. Assim, é mister reconhecer essa perspectiva - ao que tudo indica, inevitável -, e então, antever problemáticas que a adesão a esses mecanismos acarretará, exatamente para evitá-las e/ou minimizá-las.

"Os algoritmos não tornam as coisas justas se forem aplicados de forma cega e displicente. Não tornam as coisas justas. Eles repetem nossas práticas passadas, nossos padrões. Eles automatizam o status quo." (O'NEIL, 2017, tradução nossa ${ }^{9}$ ).

Diante do crescimento exponencial da colheita infindável de dados a fim de conduzir a forma de ação, a estudiosa Sarah Brayne propõe a inversão da maneira de utilização de tais dados. Isso quer dizer que, ao invés de submeter o conjunto colossal de dados colhidos pela polícia a um algoritmo que rastreie e preveja atividades criminosas e também indique, discriminatoriamente, quais são os integrantes da sociedade que apresentam maior risco de praticá-las, a socióloga sugere que sejam colhidos dados sobre as práticas policiais, a fim de possibilitar a verificação sobre de que maneira os preconceitos se manifestam nos indivíduos integrantes da instituição. (BRAYNER, 2021, p. 122).

Ocorre, nesse sentido, a inversão no foco da vigilância, com o policiamento da própria polícia. A vigilância, anteriormente direcionada aos integrantes da sociedade, passa a ser dirigida aos próprios sujeitos policiais, responsáveis pela vigilância social. Inicialmente, a observação de tais resultados possibilita evidenciar como os preconceitos enraizados nas subjetividades, e, logo, também na instituição, se manifestam nas práticas adotadas pela polícia e, posteriormente, que sejam executadas formas de atuação em sentindo contrário a tais práticas. A pesquisadora acrescenta que ësclarecer os padrões sistemáticos de preconceito no policiamento é um grande primeiro passo para aumentar a responsabilidade." (BRAYNER, 2021, p. 127, tradução nossa10).

São notados impasses na própria origem desse sistema de algoritmos, ante o desconhecimento da sociedade em geral, que são os alvos desse mecanismo de prognóstico de risco, quanto à criação e ao funcionamento do mesmo. Isso porquê desconhecemos a "lógica computadorizada" e as definições de sucesso estabelecidas por detrás, e inclusive, no que

\footnotetext{
${ }^{9}$ Do original: Algorithms don't make things fair if you just blithely, blindly apply algorithms. They don't make things fair. They repeat our past practices, our patterns. They automate the status quo.

${ }^{10}$ Do original: Shedding light on systematic patterns of bias in policing is a great first step in increasing accountability.
} 
tange a essa desinformação, a mesma é fruto do próprio capitalismo atual que, com o discurso de ser informacional, encobre a verdadeira intenção de ocultar os seus processos de funcionamento (AMARAL e DIAS, 2019, p. 6).

Como consequência, diante da ausência de transparência e clareza quanto ao alcance dos algoritmos, ou melhor, quanto ao poder da ação dos mesmos na vigilância, frequentemente somos levados a relevar e até menosprezar o constante compartilhamento e propagação dos nossos dados pessoais. Uma grande demonstração do quão imensurável é o monitoramento foi evidenciada no ano de 2013, quando Edward Snowden, ex-técnico da Agência de Segurança Nacional (NSA) dos Estados Unidos, utilizou o pseudônimo de Citizenfour para comunicar a uma jornalista as ações de espionagens feitas pelo governo norte-americano em face de cidadãos e empresas, também de outras nações, a exemplo do Brasil. Em um dos trechos das mensagens trocadas, Citizenfour asseverou à jornalista:

\begin{abstract}
"A partir de agora, saiba que todas as fronteiras que você cruza, todas as compras que você realiza, todas as ligações que você faz, todas as torres de celular que você passa, amigo que mantém, artigo que escreve, site que visita, linha de assunto digitada e pacote que encaminha, está nas mãos de um sistema cujo alcance é ilimitado, mas seus guardiões não são. Sua vitimização pelo sistema da NSA significa que você está bem ciente da ameaça que habilidades secretas e irrestritas representam para as democracias. Esta é uma história que poucos, mas você pode contar." (WIRED, 2014, tradução nossa ${ }^{11}$ ).
\end{abstract}

Além da necessidade urgente de se debater sobre o funcionamento de prognósticos de riscos, informando de forma massiva a sociedade sobre a importância da preservação dos seus dados pessoais, principalmente nessa "Era dos Algoritmos", dentro de um trabalho coletivo Harcourt apresenta a proposta de prática de policiamento randômico, argumentando que a mesma deve ser recorrida em razão de inexistir outra opção, isto é, considerar a randomização a única alternativa para nós, sociedade, agirmos dentro dos limites da razão crítica. (HARCOURT, HAREL, LEVY e O'HEAR, 2009, p. 7).

A ideia do policiamento randômico se baseia na ideia da colheita de amostragem aleatória, e isso permite que a atuação policial efetivamente afaste-se da automaticidade e guie o seu funcionamento, principalmente investigativo, por intuições e experiências anteriores. Como consequência, ainda que o preconceito e a discriminação não sejam

\footnotetext{
${ }^{11}$ Do original: From now, know that every border you cross, every purchase you make, every call you dial, every cell phone tower you pass, friend you keep, article you write, site you visit, subject line you type, and packet you route, is in the hands of a system whose reach is unlimited but whose safeguards are not. Your victimization by the NSA system means that you are well aware of the threat that unrestricted, secret abilities pose for democracies. This is a story that few but you can tell.
} 
totalmente eliminados - e isso é impossível se considerarmos que todo sujeito, inclusive policiais, é constituído de seus próprios pré-conceitos -, eles serão minimizados, haja vista que se extingue a loop discriminatório eterno ocasionado pelos algoritmos. Nesse sentido, a aleatoriedade permite "neutralizar os efeitos perversos da previsão" (HARCOURT, 2005, p. 38, tradução nossa ${ }^{12}$ ).

Alguns consideram utópica e até absurda a possibilidade da atenuação da seletividade do sistema penal - inclusive do policiamento -, em razão desta característica ser o alicerce do capitalismo vigente, bem como estar intimamente ligada a convicções individuais, subjetivas. No entanto, como acertadamente assevera a frase de autoria desconhecida - mas atribuída erroneamente a Albert Einstein -, “insanidade é fazer a mesma coisa repetidamente e esperar resultados diferentes", ou seja, o que deve ser considerada quimérica e utópica é a crença no triunfo da justiça através um sistema utilitarista e copiador de resultados guiado por um algoritmo que tenha sido alimentado por comportamentos anteriores amplamente discriminatórios.

O crescimento da adoção de prognósticos de riscos baseados em métodos estatísticos ocorre juntamente aos avanços tecnológicos, e contra estes não devemos nos opor. A resistência e a postura questionadora devem sim existir, não contra as modernizações e inovações tecnológicas, mas em face da forma de aplicação dos métodos orientados por algoritmos, os quais são incapazes de representar completamente aquilo que é justo, já que provêm de um mundo que não é igualitário. (SUMPTER, 2019, p. 72). Ademais, consoante assevera precisamente o matemático David Sumpter, a justiça é algo humano, relacionada ao que sentimos, não podendo ser representada através de uma equação matemática. (SUMPTER, 2019, p. 72).

\section{REFERÊNCIAS}

AMARAL, Augusto Jobim do; DIAS, Felipe da Veiga. Surveillance e as Novas Tecnologias de Controle Biopolítico. Veritas, v. 64, n. 1, jan.-mar, 2019.

BAUMAN, Zygmunt. Danos colaterais: desigualdades sociais numa era global. Tradução: Carlos Alberto Medeiros. Rio de Janeiro: Zahar, 2013b.

${ }^{12}$ Do original: (...) to neutralize the perverse effects of prediction. 
BRAYNE, Sarah. Predict and Surveil: Data, discretion, and the future of policing. New York: Oxford University Press, 2021.

DELEUZE, Gilles. Post-scriptum: sobre as sociedades de controle. In: Conversações. Tradução: Peter Pal Pelbart. São Paulo: Editora 34, 1992.

DIETER, Maurício Stegemann. Política criminal atuarial: a criminologia do fim da história. Rio de Janeiro: Revan, 2013.

FEELEY, Malcolm M.; SIMON, Jonathan. The new penology: notes on the emerging strategy of corrections and its implications. Criminology, Vol. 30, N. 4, 1992, p. 449-474.

GARLAND, David. La Cultura del Control: crimen y orden social en la sociedad contemporánea. Tradução: Máximo Sozzo. Barcelona: Gedisa Editorial, 2005.

GREENBERG, Andy. These are the emails Snowden sent to first introduce his epic NSA leaks. WIRED, 2014. Disponível em: https://www.wired.com/2014/10/snowdens-firstemails-to-poitras/. Acesso em: 20 jun. 2020.

HARCOURT, Bernard E. Against Prediction: Sentencing, Policing, and Punishing in an Actuarial Age, University of Chicago Public Law \& Legal Theory Working Paper No. 94, 2005.

HARCOURT, Bernard E.; HAREL, A; LEVY, Ken; e O'HEAR. Randomization in Criminal Justice: A Criminal Law Conversation, Journal Articles, 72, 2009.

MINORITY REPORT. Direção: Steven Spielberg. Produção: Bonnie Curtis; Gerald R. Molen. São Paulo: Fox Film do Brasil, 2002. DVD (145 min.).

O'NEIL, Cathy. The era of blind faith in big data must end. TED Talks, 2017. 1 vídeo (13 min). Disponível em:

https://www.ted.com/talks/cathy_o_neil_the_era_of_blind_faith_in_big_data_must_end. Acesso em: 14 maio 2020.

O’NEIL, Cathy. Weapons of Math Destruction. Talks at Google, 2016. 1 vídeo (58 min) Disponível em: https://talksat.withgoogle.com/talk/weapons-of-math-destruction. Acesso em: 14 maio 2020.

PILATTI, Adriano. Expansão do medo aumenta mecanismos de controle e vigilância. Revista IHU Online, 2016. Disponível em: http://www.ihuonline.unisinos.br/artigo/6655-adrianopilatti-4. Acesso em: 17 maio 2020.

PRE-CRIME. Direção: Matthias Heeder e Monika Hielscher. Berlin: Kloos \& Co. Medien $\mathrm{GmbH}, 2017$ (88min).

STREVA, Juliana Moreira. Auto de resistência, biopolítica e colonialidade: racismo como mecanismo de poder. Revista Brasileira de Ciências Criminais, São Paulo, v. 38, p. 237267, dez. 2017. 
WACQUANT, Loïc. As prisões da miséria. Tradução: André Telles. Rio de Janeiro: Jorge Zahar, 2001. 